\title{
Behavior Research, Direct
}

National Cancer Institute

\section{Source}

National Cancer Institute. Behavior Research, Direct. NCI Thesaurus. Code C15770.

Research concerning people's behavior in the context of cancer, i.e., how people's behavior affects their chance of developing cancer. 